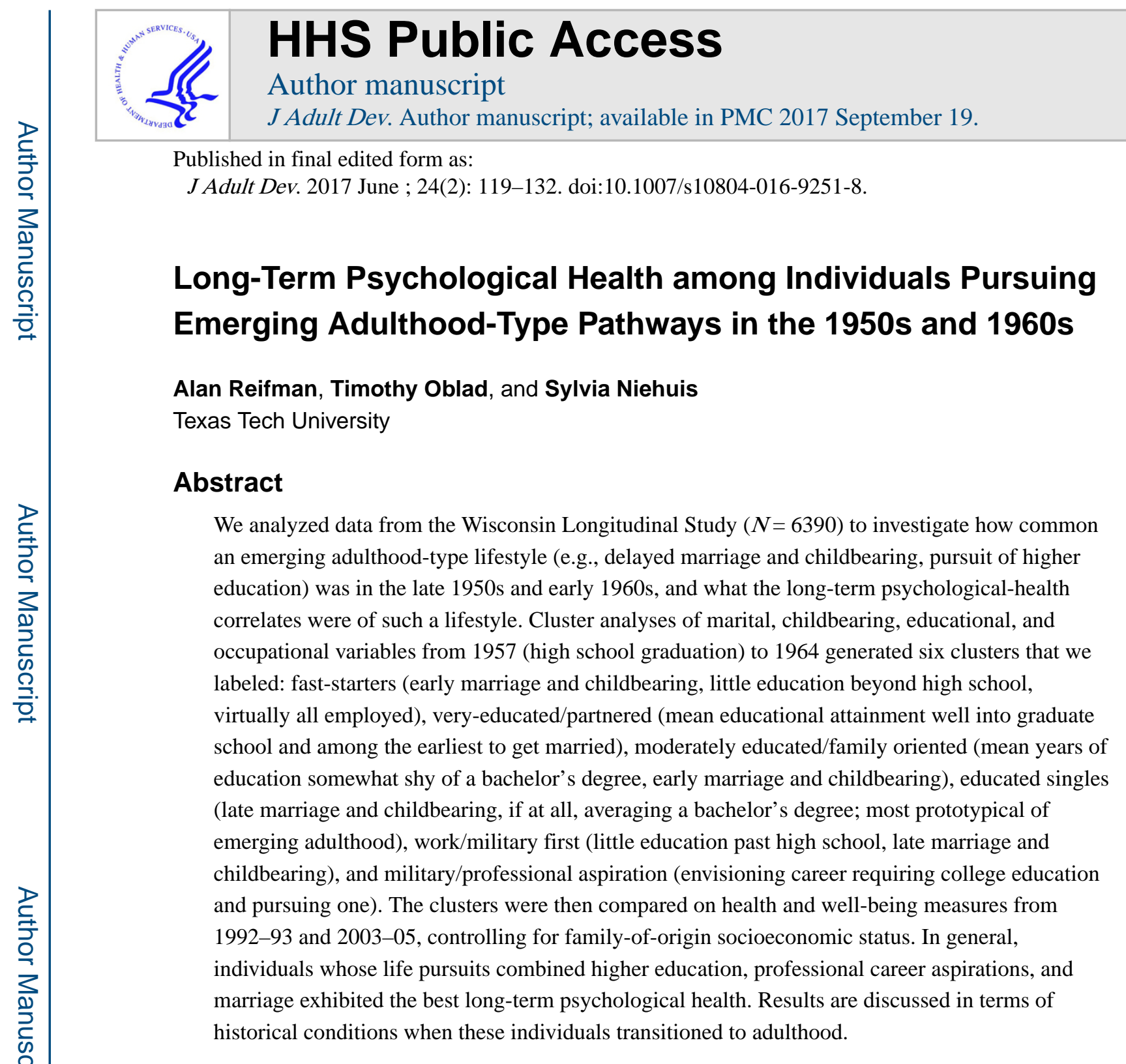

\title{
Keywords
}

Emerging adulthood; 1950s; health; Wisconsin Longitudinal Study

My starting point is the belief that to understand the courses and processes of development... it is necessary to situate them in the historical context of the social and cultural conditions of a society. - Hideo Kojima (2003, p. 72)

Individuals vary in their transitions to adulthood. Many options theoretically are available, such as pursuing higher education or not; marrying early, waiting to marry, or planning not to marry at all; trying to have children or not; and entering one line of work vs. another (or opting for a stay-at-home role). Young people have some choice in these matters, but economic factors and societal norms - which may vary across historical eras - can constrain

Correspondence should be directed to Alan Reifman, Department of Human Development and Family Studies, College of Human Sciences, Texas Tech University, Lubbock, TX 79409-1230. alan.reifman@ @tu.edu (phone: 806-834-5174; fax: 806-742-0285).

Timothy Oblad is now at Texas A\&M University-Kingsville. 
one's opportunities. The present study attempts to capture the diversity of trajectories to adulthood in a particular cohort (those graduating from high school in 1957), using the Wisconsin Longitudinal Study (WLS). We situate WLS participants within their sociohistorical context, examining how well their various trajectories into adulthood (e.g., if/when they married, whether they pursued higher education) fit with the social norms of the time, and how this fit predicts psychological health roughly $35-50$ years later. By doing so, the study addresses questions such as these: Will those participants who followed a traditional pathway to adulthood for the 1950s and 1960s (i.e., early marriage and childbearing) report better or worse psychological health at midlife than participants following an unconventional pathway? What will the psychological health consequences be for those participants who, more than a half-century ago, chose to follow a pattern that today would be described as resembling emerging adulthood (i.e., delayed marriage and childbearing, and pursuit of higher education; Arnett, 2000, 2004)? By looking at each individual's combination or configuration of roles (e.g., married, no children, employed, no military service), with sorting of similar individuals into clusters, the present study offers what might be considered a "morphogenic" perspective (Allport, 1962; Pelham, 1993) on development. Our study also allows one to speculate about the consequences of today's youth trajectories toward adulthood, their fit with current societal norms, and their future health consequences.

Of the many possible pathways adolescents could follow into adulthood in recent decades, none has received so much attention as emerging adulthood (EA; Arnett, 2000, 2004). At a general level, EA has been characterized as the time between the end of adolescence and the onset of full-fledged adulthood, with its accompanying roles of spouse, parent, full-time employee, etc. This period has mainly been associated with the seven years between ages 18-25, although more recent accounts have cited longer age ranges (e.g., 18-29; Arnett, Žukauskienè, \& Sugimura, 2014). Some researchers contend, however, that not all 18-29 year-olds should be described as emerging adults (Reifman, Arnett, \& Colwell, 2007). A key element of emerging adulthood is prolonged exploration, in romantic relationships, careers, and sociopolitical views (Arnett, 2000, 2004). Thus, only those youth who delay marriage and childbearing, pursue higher education (and possibly post-graduate studies), and explore different possible careers would be considered emerging adults, according to this perspective. Individuals who approach adulthood differently, such as those Osgood, Ruth, Eccles, Jacobs, and Barber (2005) refer to as "fast starters" for their early marriage, childbearing, and employment, would not be considered emerging adults. Although not all 18-29 year-olds are necessarily emerging adults, large segments of the U.S. population appear to be exhibiting markers of EA. As of 2015, men's median age at first marriage had risen to nearly 29 and women's to nearly 27 (U.S. Census Bureau, 2015), compared to the period from 1950-1970, when men's median age at first marriage was stable at 23 and women's at around 20 (Arnett, 2004). The transition to parenthood has followed a similar pattern (Leonard, 2016; Mathews \& Hamilton, 2009). Arnett explicitly situated emerging adulthood within a particular historical-economic era, namely the "information age" of the late 1990s and into the 2000s, when the pursuit of higher education characteristic of EA would match societal norms. In the late 1950s and early 1960s, however, an EA lifestyle of delaying marriage, children, and employment in favor of pursuing higher education would be counter-normative, hence our primary interest in EA. 
As noted, Arnett's $(2000,2004)$ theorizing on emerging adulthood has coincided with the postindustrial information age. This era's requirement of advanced education for jobs related to computers, software, and other forms of high technology (Miller, 2002) has likely driven some of the trends associated with EA. Some authors consider information-age fields also to include "creative class" and knowledge-based workers such as architects, engineers, socialservice professionals, lawyers, teachers, artists, designers, and media professionals (Florida, 2002; Judis \& Teixeira, 2002). Skill sets expected from employees in these latter fields have increased over time (Florida, 2002; Settersten \& Ray, 2010), contributing further to increased education-seeking and delayed marriage and childbearing in emerging adulthood. In addition to career pursuits, the EA lifestyle can include exploration in the form of travel, volunteer work, and internships to crystallize one's values, career interests, etc. (Arnett, 2004), at least for those young people whose families are well-enough off to permit such non-paid activities. Tying together some of these threads, Krahn, Howard, and Galambos (2015) postulate a link between education and exploration. These authors found more frequent educational transitions (e.g., going to college for a while, then leaving, then returning) between ages 19-25 to be associated with greater occupational progress by age 32 , suggesting that experimenting with different educational training programs may be a productive form of exploration rather than a form of floundering (Krahn et al., 2015).

\section{Social-Historical Perspective}

Even though features associated with emerging adulthood - pursuit of advanced education, delayed marriage and childbearing - have become widespread in recent decades, historically, there have always been at least some people displaying these features (Kloep \& Hendry, 2011). However, there appears to be little research looking at associations between emerging-adult lifestyles of varying congruity with dominant social norms and psychological-health outcomes decades later. Elder's (1974) longitudinal study of children of the Great Depression is an exception. It followed families differentially impacted by the Depression and their grown-children's health as they approached 40 years of age. The present study likewise takes a social-historical perspective, using a unique dataset (the Wisconsin Longitudinal Study) to investigate individuals transitioning to full-fledged adulthood in the late 1950s and early '60s, and the long-term psychological-health correlates associated with pursuing different pathways to adulthood. This approach of integrating historical scholarship with quantitative social sciences such as sociology and psychology (McDonald, 1996; Stewart \& Healy, 1989; Twenge, 2015) is not new, of course. Much of this type of research examines how characteristics of individuals interact with characteristics of an historical era (e.g., individuals who were young in a turbulent era such as that around the Great Depression and World War II; Stewart \& Healy, 1989). It is rooted in the idea that to fully understand the choices people make in life with regard to life's most important social roles (such as making a life-time commitment to another person or becoming a parent) requires an understanding of the socio-historical context in which these choices are made (Helson \& Picano, 1990).

An important theme in the present study is the importance of social norms and the psychological-health consequences for those who violate them. Bicchieri (2006) discusses how people's willingness to impose sanctions on deviants is a key part of norms' operation. 
One form of deviation from social norms is being "off-time" (i.e., of an unconventional age) when one takes on a particular role. Settersten (1998) studied how people would respond to deviation from norms, such as when individuals should move out of their parents' home. Many respondents reported no consequences for such deviation, whereas others cited "interpersonal sanctions" such as harassment and being gossiped about. Regarding the employment domain, Moen (2016) notes that off-time workplace entries or exits may create stress or disruption in one's life. Steady exposure to negative sanctions and stressful events likely would harm the short-term (if not the long-term) psychological health of individuals who violate social norms. As well, negative feedback for violating norms would likely affect individuals' perceived success in those domains valued by society (i.e., family, work, finances), compared to individuals who followed more conventional life paths relative to their historical contexts. The present study includes survey items measuring respondents' demographic characteristics in the 1950s and 1960s (e.g., marital and parental status, education) and psychological health in the 1990s and 2000s. Respondents' awareness of the social norms of their youth, their exposure to people who enforced the norms, their perceptions of how much they personally were influenced by the norms, etc., were not measured. Thus, our discussion of likely mechanisms linking marriage, education, and other demographic transitions in the 1950s and 1960s to later psychological health is purely inferential.

WLS participants (1957 high school graduates) were born in the latter part of the "Silent Generation" (1925-1945; Alsop, 2008), which included the aforementioned Great Depression/World War II era. These 1957 graduates would have transitioned to adulthood during the Baby Boom (born 1946-1964; Alsop, 2008), in which marriage and childbearing were rampant. Arnett (2004) argues that a desire for stability after World War II drove family formation, but it is also worth noting that the rebounding post-war economy of the 1950s also likely spurred the trend. In this context, delaying marriage well beyond high school in the 1950s would likely have been met with suspicion, worry, and disapproval by family members and society at large, given the social norms at the time. In the 1950s and early 1960s, single adults were both few in number (in 1960, "only 10 percent of women age 25-29 were not married") and stigmatized as immature and psychologically defective; singles reportedly were even denied bank loans, promotions on the job, and prescriptions for contraception (Coontz, 2011). However, societal attitudes toward delaying marriage became more favorable in the 1970s and beyond (Thornton \& Young-DeMarco, 2001; Veroff, Douvan, \& Kulka, 1981), suggesting that negative effects on unmarried persons' psychological health may have diminished.

Societal perceptions of women working in the paid labor force also changed dramatically. In the 1950s, career-oriented women were the exception rather than the norm (Helson, 1972). Longitudinal research on college women from the late 1950s to when they were 43 years old in the 1980s has noted a shift in societal norms over this period of time toward greater acceptance of women's career aspirations and labor-force participation (Helson \& Picano, 1990).

An additional difference between the Silent and Baby Boom Generations, on the one hand, and the Millennials (born 1980-2001; Alsop, 2008), on the other, is the prevalence of 
military service. Such service was more common in the late 1950s and early 1960s (in between the Korean and Vietnam Wars) than in the 1980s and beyond (Segal \& Segal, 2004, Figure 1). A military draft for men had existed from 1940-1973, before the U.S. switched to an All-Volunteer Military (Congressional Budget Office, 2007). Accordingly, the present study of 1957 high-school graduates will include military service as a component of individuals' life-trajectories, along with marriage, childbearing, education, and labor-force participation.

\section{Heterogeneity in Pathways to Adulthood}

One approach to studying diverse transitions to adulthood is to classify individuals into groupings that represent different pathways (e.g., early family formation and employment; delayed marriage while seeking advanced education). Researchers have found cluster analysis and related techniques such as latent class analysis (LCA) to be useful for this purpose. Two examples are the studies by Osgood et al. (2005) and Sandefur, EggerlingBoeck, and Park (2005). Osgood et al. applied LCA to 24-year-old participants (born in 1972) from mostly white working- and middle-class suburbs in the Detroit, Michigan area. Variables represented five possible transitions: romantic relationship (single, dating, cohabiting, married), parenthood, residence (with parents, or in own apartment or house), education, and employment. The LCA yielded six groupings, which Osgood and colleagues labeled: fast starters (12\% of participants; characterized by high rates of marriage, parenthood, living apart from parents, and being established in the labor force, but rarely with a college degree); parents without careers (10\%; married, with children, living apart from parents, but little progress in work or education beyond high school); educated partners (19\%; married or cohabiting in high numbers, heavily involved in higher education, generally without children); educated singles (37\%; similar to the previous group, except not partnered and largely living with their parents or in apartments); working singles (7\%; characterized mainly by working in the labor force and living with parents); and slow starters (14\%; little progress toward living independently from parents and finding work with long-term prospects).

Sandefur et al. (2005) used data from two national surveys (High School and Beyond 1992, when respondents were 28; and the National Education Longitudinal Survey 2000, when participants were 26). LCA, conducted separately in men and women in each of the two data sets, yielded four classes in each gender group. A group of married parents with "limited postsecondary education" emerged in both men and women. Two additional groups (present in both men and women) had attained Bachelor's degrees, but differed in whether they had started families. The fourth men's group exhibited a limited-education/no-family profile, whereas members of the fourth women's group tended to have limited education, be unmarried, and have a child.

Across the Osgood et al. and Sandefur et al. studies, there appear to be some common groupings: Individuals in their mid-20s, characterized by extensive education, possible romantic partnering, but no children, would be considered most emerging adult-like. In contrast, those with less education and more extensive family formation would be considered least characteristic of emerging adulthood. 
The present study assumes that similar groupings can be extracted from individuals who transitioned to adulthood in the late 1950s and early 1960s, albeit with smaller numbers of people pursuing advanced education and remaining unpartnered, and with the inclusion of military service factored in. In the draft era (i.e., pre-1973), it was common for senior officers to have spouses and children and to serve for a longer period of time, whereas this was not so much the case for young soldiers who typically returned to civilian life after a short stint in the military to begin their careers and start their own nuclear families (Clever \& Segal, 2013). In contrast to Osgood et al. (2005) and Sandefur et al. (2005), who did not report health differences between their clusters, the present study predicted later psychological health (i.e., depressive symptoms and psychological well-being) from cluster membership. Because trajectories into young adulthood (e.g., early vs. later marriage, pursuit or non-pursuit of higher education) may well be confounded with socioeconomic status (SES) in the family of origin, all analyses controlled statistically for family SES. We offer the following hypotheses:

H1: Cluster analysis of marital, childbearing, educational, and occupational variables from the WLS will yield similar groupings to those obtained in later decades by Osgood et al. (2005) and Sandefur et al. (2005). However, clusters characterized by early marriage and family formation will comprise larger proportions of the sample in the WLS than in Osgood et al.'s and Sandefur et al.'s studies, and clusters grounded in extensive education will include a lower proportion of WLS respondents than in the Osgood et al. and Sandefur et al. studies.

H2: Emerging adult-type clusters from the WLS will differ from their more traditional counterparts in long-term psychological health (i.e., 1990s and 2000s assessments). We suspect the social climate of the 1950s and early 1960s, which was uncongenial to the unmarried, would have harmed the psychological well-being of the emerging adult-type clusters at that time. However, the WLS did not measure psychological well-being until the 1990s. It is possible that deviation from societal norms as young adults during the 1960s could have had lingering negative effects on the midlife psychological health of those following the emerging adult-like pattern, relative to individuals who adhered to those norms in young adulthood. However, the former group's extended education (which likely correlates with less physical labor, better medical care, and greater financial benefit over the long term) and increasingly tolerant societal attitudes toward prolonged singlehood could well have promoted better psychological health than that of individuals who pursued early marriage, childbearing, and employment in the 1960s. Given these considerations, we are open to the "emerging adults" of the 1960s having either worse or better midlife psychological health than those who followed the conventions of the time.

H3: In the 2003-05 assessment, when respondents were in their mid-60s, subgroups who followed a traditional (i.e., early marriage and childbearing) pathway would report (a) greater self-perceived family success, (b) less perceived work success, and (c) less perceived financial success than the more emerging adult-type clusters. Early marriage and childbearing would have provided companionship from adult children and increased the chances of having grandchildren and a rich extended-family life, factors that should increase perceptions of family success. However, the kinds of jobs landed by those who pursued 
work and family immediately following high school likely would have had limited advancement in the following decades, diminishing these individuals' sense of work and financial success.

\section{The Present Study}

The present investigation, using the Wisconsin Longitudinal Study, is eminently suited to investigate how common (or rare) an emerging adulthood-type lifestyle was in the late 1950s and early 1960s, and what the long-term psychological-health correlates were for a lifestyle that deviated from the social norms of the time. The WLS surveyed graduates from the state's high schools in 1957 and continued to follow participants into the new millennium. In addition to containing all of the key variables necessary to construct similar clusters to those of other investigators, it also assessed self-reported psychological health at midlife, such as depressive symptoms, self-concept (e.g., sense of purpose, sense of control), and participants' self-rated success in the family, work, and financial domains. The present investigation thus was able to follow a two-stage process with WLS data: forming clusters of participants based on their family/relationship, educational, and work characteristics from high school and the immediately following years, and then comparing the clusters on indicators of psychological health and well-being further on in adult life, up to when respondents were in their mid-60s.

\section{Method}

\section{Sample}

The Wisconsin Longitudinal Study was launched in 1957, with an attempt to survey all of the state's high school graduates that year; a one-third sample of the graduates was used for all subsequent waves (Wahlberg, 2007). Details of the project are available on the WLS website (see Author Notes). Assessment waves have taken place roughly once a decade, except for none in the 1980s. We used data from 1957, 1964, and 1975 to develop the earlyadulthood profiles, and the 1992-93, and 2003-05 waves to investigate outcomes later in adulthood. The original sample size was 10,317 . As of the mid 2000s, approximately 7,300 people were still participating (Wahlberg, 2007). Due to missing data on the variables used to derive the clusters, the number of respondents sorted into clusters was $N=6390$, with 3,427 men (53.6\%) and 2,963 women (46.4\%). For depressive symptoms, the necessary items were administered not to the full sample but to a 79\% random sample in 1992-93, with the same people in this $79 \%$ subsample being asked the same items again in 2003-05. Other forms of missing data, such as incomplete interviews, were rare (approximately 1-3\% on most variables).

\section{Measures}

All measures used in the present study were obtained via phone interview, unless noted otherwise; mail and Self-Administered Questionnaire (SAQ) were the other data-collection modes. An overall guide to WLS instrumentation from 1957-2010 (Pearce, Parks, et al., 2011) is available online. Data collection modes are summarized in Herd (2010), whereas 
scale-construction and reliabilities are described in WLS (2008). Measures used in the present study are also summarized in the following paragraphs.

Early-adult pursuits-We examined nine items to characterize respondents' earlyadulthood profiles. Three items from the 1957 (high school senior-year) survey were used to measure interest in higher education and career plans: "How necessary is a college education for the work you want to do?" (1 = necessary to 3 = unnecessary, SAQ), "To what extent have you discussed your plans with your teachers or counselors?" and "To what extent have you discussed your plans with your parents?" (for the latter two items: $1=$ not at all to $3=$ very much). An additional 1957 item asked "Has marriage or the prospect of being married influenced your plans for next year" $(1=$ yes, $2=n o)$.

Items from 1964 assessed participants' highest educational attainment to that point $(12=$ no post-high school education, through 16 = bachelor's degree or university nursing education, to $20=$ Ph.D., J.D., M.D., and similar degrees; mail) and whether they worked in the labor force that year $(1=y e s, 0=n o$; the military was included as being employed $)$. Finally, three items measured in 1975 assessed the timing of first marriage and of having one's first child (if these events occurred) and whether the respondent had served in the military. The marital and childbearing history variables were constructed in the same way. Respondents reported the years in which they experienced these events, which were converted to four-level ordinal variables for the present study: up through 1964 (coded as 1), 1965-1970(2), 1971-1975

(3), or not married/no children by 1975 (4). Under this format, which allowed unmarried and childless individuals to be included, a higher score represents greater delay of the respective milestone. Military service as of 1975 was measured as yes (1) and no (0). Using the above items, an emerging-adulthood trajectory would be characterized by greater discussion with teachers/counselors and parents of educational and career plans; aspiration toward a career requiring higher education; attainment of college or postgraduate education; immediate posthigh school plans not being influence by the prospect of marriage; and long delays in marriage and childbearing. Being in the labor force and/or military as of 1964 (roughly age 25 ) or in later years was not necessarily indicative of being an emerging adult. One could have a job that he or she saw as part of an exploratory phase toward a more stable career, or the job could constitute a stable career (e.g., one could have graduated from law school by age 25 and be starting out in what he or she sees as a stable career as a lawyer). However, because paid employment and military service play major roles in many persons' adult lives, they were used in the analyses.

Psychological health-Several measures of psychological health were used. Depressive symptoms were measured in the 1992-93 and 2003-05 waves with the Center for Epidemiologic Studies-Depression scale (Radloff, 1977). The CES-D was administered by mail survey. Respondents were asked to rate the frequency with which they had experienced various symptoms (e.g., "feel sad," "feel everything you did was an effort") within the past week (20 items in all; including a few reverse-scored items, such as "feel happy"). The WLS modified the CES-D by offering response choices from $0-7$, corresponding to the exact number of days in the past week the symptom was experienced; the original instrument used a four-point scale based on approximate numbers of days (e.g., 1-2 days, 5-7 days). Internal 
consistency (alpha) reliability was reported to be .90 in the 1992-93 WLS and .88 in the 2003-05 version.

Ryff's measure of psychological well-being (Ryff, 1989; Ryff \& Keyes, 1995; Springer \& Hauser, 2006) provided subscales for aspects of self-concept and life outlook. This instrument was administered in the 2003-05 phase by mail. The six subscales, along with sample items and alpha reliabilities, are as follows: self-acceptance ("In general, I feel confident and positive about myself"; $\alpha=.78$ ), positive relations with others ("To what extent do you agree that people would describe you as a giving person, willing to share your time with others?;" $a=80$ ), autonomy ("To what extent do you agree that you are not afraid to voice your opinions, even when they are in opposition to the opinions of most people?;" a $=.65$ ), purpose in life ("To what extent do you agree that some people wander aimlessly through life, but you are not one of them?;" $a=.69$ ), environmental mastery ("To what extent do you agree that you are quite good at managing the many responsibilities of your daily life?;" $\alpha=.75$ ), and personal growth ("To what extent do you agree that you have the sense that you have developed a lot as a person over time?;" $a=.74)$. All subscales were based on five items each, except for purpose in life, which had six. Item response options ranged from agree strongly (1) to disagree strongly (6), with reverse-scoring as needed so that high scores represent more of the respective constructs.

Life success-The 2003-05 survey included a set of items about, “...how successful you think you've been in various areas of your life." Items had the stem, "How successful have you been...," followed with the domains "in work," "financially," and "in your family life." Options ranged from not at all successful (1) to very successful (4). The item pertaining to success in education was asked only to $20 \%$ of the sample, so was not used here.

Family-of-origin socioeconomic status-Several variables were available in the dataset to use in controlling for respondents' family SES and social class while growing up. Many of them had extensive missing data, however. One variable, called ses 57 with the label "Factor-Weighted SES score for parents," had no missing data and was thus used. It was created from father's and mother's years of schooling, Duncan's Socioeconomic Index (SEI) for the father's 1957 occupation, and average parental income. Further detail on creation of ses57 is available at WLS (1999).

\section{Results}

\section{Descriptive Information}

The vast majority of WLS respondents had married by 1964, when they were roughly 25 years old (74.5\%, including small percentages who had divorced, been widowed, or died themselves after marrying). Although a comparison between a state sample and a later national one warrants caution, we note that according to 2009 national figures, only $26 \%$ of U.S. 25-year-olds had married (Payne, 2011). Further, 62.4\% of WLS respondents had had a child by roughly age 25 , whereas only $33 \%$ of U.S. 25-year-olds had done so as of 2009 (Payne, 2011). Whereas military service was more common (57\%) than not among men in the WLS, only $1 \%$ of women had military experience. 


\section{Cluster Analysis}

We submitted the following variables to a $k$-means iterative cluster analysis: timing of first marriage (unmarried treated as most delayed), whether respondents felt their plans were influenced by marriage, timing of first childbirth (childless treated as most delayed), necessity of college education for chosen career, educational attainment, degree to which the respondent discussed his or her plans with teachers and counselors, degree to which they discussed plans with parents, whether respondent served in the military, and workforce participation in 1964.Two of these variables - having plans influenced by marriage, and discussing plans with parents - were dropped because their means did not differ greatly between the clusters. Initial analyses using the default option in SPSS suggested a six-cluster solution. Cluster centers were selected and updated as the computer program scanned down the data file, thus making final cluster composition with $k$-means iterative analysis sensitive to the order in which cases were listed (IBM, not dated). To overcome this problem, we randomly re-sorted the cases five times and performed a cluster analysis on each of the resulting data sets. To assess the robustness of the clustering solutions, similarity between each solution and each other one (ten paired comparisons in all; i.e., Solution A with B, A with C, through to D with E) was examined via cross-tabulations and kappa coefficients (Reilly, Wang, \& Rutherford, 2005). According to Viera and Garrett (2005), kappa values from .61-.80 indicate "substantial" agreement, whereas anything higher represents "almost perfect" agreement. Four of our cluster solutions (A-D) were related to each other with a kappa of at least .70. Solution E related well only to Solution D (kappa =.72). Solution D had the highest average kappa relationship with all of the other solutions (mean kappa $=$. 75), so it was adopted for the major analyses. The six clusters from Solution D are summarized as follows:

A fast-starter group emerged as the largest cluster in the WLS (54.9\% of sample; $n=3,506$ out of 6,390 participants with the necessary data). Members of this cluster tended, on average, to marry early (mean of 1.10, with a score of 1 representing marriage by 1964), have children early (mean of 1.22 on the same scale), not consider college as necessary for their chosen line of work (mean of 2.39, where 3 represents "unnecessary"), obtain little education beyond high school (mean of 12.27 years), have little discussion of future plans with teachers or counselors (mean of 1.74, where 1 equals "not at all"), and be working in the labor force (99\%). Thirty-two percent of the fast-starters served in the military, roughly equal to the overall sample average. The relative size of this WLS fast-starter group was far larger than Osgood et al.'s (2005) fast-starter group (12\%).

Two clusters emerged representing variations on the educated-partner theme. Very-educated/ partnered participants $(4.8 \% ; n=305)$ on average amassed a great deal of education (mean of 18.12 years), had considered a college education important to their future work (mean of 1.10 , with $1=$ "necessary"), and had discussed these matters extensively with teachers and counselors (mean of 2.21 , with $3=$ "very much"). This group married relatively early (mean of 1.38), but appeared to delay somewhat in having children (mean of 1.97, with $2=1965-$ 1970 , corresponding roughly to participant ages 26-31). Members of this group had relatively low involvement in the paid labor force as of 1964 (53\%), presumably because many of them were still in graduate school. 
Members of the moderately educated/family-oriented cluster $(20.6 \% ; n=1,319)$ on average obtained close to a bachelor's degree (mean of 15.46 years), considered a college education necessary for their chosen career field (mean of 1.22), and engaged in moderate discussion with teachers and counselors (mean of 2.08). Members of this group married (mean of 1.10) and had children (mean of 1.33) early. Ninety-six percent were in the labor force as of 1964. The present group and the very-educated/partnered group in the WLS, who shared an emphasis on family and education, comprised a combined $25.4 \%$ of the sample. This percentage is somewhat higher than the proportion of Osgood et al.'s (2005) respondents who were classified as educated-partners (19\%).

An educated-singles group also emerged $(4.3 \% ; n=272)$. These participants averaged a bachelor's degree (mean of 16.03 years), considered college education necessary (mean of 1.23), and engaged in a moderate amount of discussion with teachers and counselors (mean of 2.05). These participants had late onsets of marriage (mean of 3.79, with $3=1971-1975$ or roughly ages 32-36, and 4 represents never-married as of 1975) and childbearing (mean of 3.93, on the same scale), if they experienced these milestones at all. This group's 1964 labor-force participation rate (81\%) was below some of the other groups. Osgood et al.'s (2005) educated-singles group was far larger (37\%) than the corresponding group in the WLS.

The work/military-first group was characterized by military service and/or paid labor appearing to occur before other pursuits $(9.2 \% ; n=591)$. This group's rate of military participation as of 1975 (42\%) was one of the highest. Broken down by gender, $68.0 \%$ of men in this cluster served in the military, whereas $1.3 \%$ of women did; thus, men's and women's similarity within this cluster occurred on characteristics other than actual military experience. Ninety-five percent of cluster members were in the labor force (or military) as of 1964 (92\% of men, 99\% of women). Marriage (mean of 2.38) and childbearing (mean of 3.79) occurred late, if at all. Further, members of this cluster neither had much formal education beyond high school (mean of 12.36 years), nor considered college necessary for their career plans (mean of 2.32).

Finally, there was a military/professional-aspiration cluster $(6.2 \% ; n=397)$. This group's rate of military service (44\%; $74 \%$ in men, $2 \%$ in women) was similar to the other military group's. Eighty percent of cluster members were in the labor force (or military) as of 1964 (69\% of men, $95 \%$ of women). However, the military/professional-aspiration group reported both a greater career-based need for higher education (mean of 1.30) and actual educational attainment (mean of 14.99 years) than did the work/military-first group. In addition, the military/professional-aspiration group reported earlier marriage (mean of 1.66) and childbearing (mean of 2.93) than their military counterparts.

On the whole, Hypothesis 1 was largely supported. The fast-starter profile was more common in the WLS than in the later research (Osgood et al., 2005), whereas the educatedsingle profile was far less common in the WLS than in the later research. Contrary to expectation, the educated-partner clusters comprised relatively similar proportions in the WLS and later research. 
In terms of gender, three of the clusters were relatively evenly divided between men and women: fast-starter (men $51.1 \%$, women $48.9 \%$ ); moderate-education/family-oriented (men $50.2 \%$, women $49.8 \%$ ); and educated singles (men $54.4 \%$, women $45.6 \%$ ). Two of the clusters had somewhat more pronounced skew in the male direction: military/professionalaspiration (men 58.7\%, women 41.3\%); and work/military first (men $60.7 \%$, women $39.3 \%$ ). Finally, the very-educated/partnered group was heavily male (men $77.0 \%$, women $23.0 \%)$. Analyses comparing the clusters on the psychological-health outcomes thus included gender as a factor.

\section{Cluster Comparisons on Psychological Health}

Depression-Two separate analyses with depressive-symptoms as the dependent variable - once when assessed during 2003-05 and one for 1992-93 - were conducted. Each followed a 2 (gender) X 6 (life-pathway cluster) Analysis of Covariance (ANCOVA) design, with family-of-origin SES serving as the covariate. All reported means are adjusted for the covariate. The ANCOVA for 2003-05 depression symptoms yielded significant effects for cluster, $F(5,4512)=9.00, p<.001$; and gender, $F(1,4512)=8.70, p<.01$; but no interaction between them $(p=.10)$. Women $(M=14.21)$ scored higher than men $(M=12.36)$ on average on 2003-05 depression symptoms. Means for the cluster groups are shown in Table 1. The work/military-first group $(M=16.18 ; 95 \%$ confidence interval $[C I]=14.80$ to 17.56) exhibited the highest mean depression symptoms in the 2003-05 wave. Identifying statistically significant differences between pairs of means in terms of non-overlap in their CIs is very conservative (Payton, Greenstone, $\&$ Schenker, 2003), as two means can still differ significantly when their CIs partially overlap. A conservative approach seems warranted given the large sample size in the present study. Regarding the work/military-first group, the lower bound of its CI was still higher than nearly every other group's upper bound. The very-educated/partnered ( $M=11.11 ; C I=9.03$ to13.20) and moderately educated/family-oriented ( $M=11.35 ; C I=10.50$ to 12.21$)$ groups had low depressive symptoms. The latter two groups' CIs did not overlap with that of the fast-starters ( $M=$ 14.03; $C I=13.48$ to 14.58 ). The moderately educated/family-oriented group's CI also did not overlap with the educated singles' ( $M=14.27 ; C I=12.26$ to 16.28).

For 1992-93 depressive symptoms, the ANCOVA yielded significant effects of lifetrajectory cluster, $F(5,4609)=4.85, p<.001$, and a Cluster X Gender interaction, $F(5$, $4609)=3.85, p<.01$, with the gender main effect just outside of conventional significance, $F(1,4609)=3.69, p=.055$. Means for the 12 cells representing combinations of clusters and gender are shown in Table 1. The highest average depressive symptoms were observed among women in the work/military-first group $(M=19.87 ; C I=17.53$ to 22.22). As noted above, women in this cluster predominantly had early experience in the paid labor market rather than in the military. Female fast-starters $(M=18.51 ; C I=17.65$ to 19.37$)$ and male educated singles ( $M=17.26 ; C I=14.37$ to 20.16$)$ also had high means. The lowest depressive-symptom mean belonged to very-educated/partnered women $(M=13.66 ; C I=$ 9.81 to 17.51). Confidence intervals for some of the highly educated subgroups were wide due to relatively small sample sizes. The moderately educated/family-oriented men ( $M=$ 14.34; $C I=13.00$ to 15.68$)$ and women $(M=14.06 ; C I=12.75$ to 15.37$)$ were relatively low in depressive symptoms and had narrower CIs. Hence, the groups highest and lowest in 
mean depressive symptoms had non-overlapping CIs in many instances, reflecting significant differences.

Psychological well-being-With Ryff's six subscales reflecting a common theme of psychological well-being, the subscales served as multiple dependent variables in a Multivariate Analysis of Variance (MANOVA). Grice and Iwasaki (2007) urged researchers to conduct "truly multivariate" analyses, meaning that MANOVA should not be treated like a series of univariate ANOVAs. Instead, researchers should use the weighting coefficients available in MANOVA to create and interpret composites of the dependent variables. An overall MANOVA with cluster groups as the only independent variable was significant, $F$ $(30,22820)=11.53, p<.001$ (based on Pillai's trace, which appears to be the most robust MANOVA statistic; Manly, 2005). Unstandardized coefficients for the first set of weights (which are more strongly associated with the independent variable than the later sets of weights) were as follows:

$(-.03 \mathrm{X}$ autonomy $)+(-.03 \mathrm{X}$ environmental mastery $)+(-.13 \mathrm{X}$ personal growth $)+$ $(.13 \mathrm{X}$ positive relations with others $)+(-.17 \mathrm{X}$ purpose in life $)+(.02 \mathrm{X}$ selfacceptance)

Ignoring the coefficients close to zero, one can thus interpret high scores on the composite as representing more positive relations with others, but less personal growth and purpose.

Conversely, low composite scores could be interpreted in terms of more personal growth and purpose, but lesser positive relations with others. The composite was computed and used as the dependent variable in a regular ANOVA with clusters and gender as independent variables and family-of-origin SES as covariate. The only significant effect in the ANOVA was that of cluster, $F(5,4558)=37.31, p<.001$. Cluster-group means on the composite are shown in Figure 1. Composite means for the fast-starter $(M=-5.67 ; C I=-5.71$ to -5.63$)$ and work/military-first groups ( $M=-5.65 ; C I=-5.75$ to -5.55$)$ suggested that positive relations with others were the main source of these participants' psychological well-being. The very-educated/partnered group ( $M=-6.39 ; C I=-6.54$ to -6.24$)$ was furthest in the direction of deriving its well-being from personal growth and sense of purpose; its CI was non-overlapping with those of the moderately educated/family-oriented $(M=-6.07 ; C I=$ -6.14 to -6.01$)$ and military/professional-aspiration $(M=-5.95 ; C I=-6.07$ to -5.83$)$ groups.

\section{Cluster Comparisons on Perceived Life Success}

Because the measures of perceived success in work, finance, and family represented a conceptually coherent set of dependent variables, MANOVA was again run; cluster groups served as the only independent variable. The overall test was significant, $F(15,14187)=$ $15.48, p<.001$. Unstandardized coefficients for the first set of weights were as follows:

$$
(-1.26 \mathrm{X} \text { work success })+(-.93 \mathrm{X} \text { financial success })+(.67 \mathrm{X} \text { family success })
$$

One can thus interpret high scores on the composite as signifying greater self-perceived family success, but lesser financial and work success; low scores represent greater financial and work success, but lesser family success. The composite was computed and used as the dependent variable in a regular ANOVA with clusters and gender as independent variables 
and family-of-origin SES as covariate. The ANOVA showed a significant main effect of cluster, $F(5,4722)=27.54, p<.001$, and a Cluster $\mathrm{X}$ Gender interaction, $F(5,4722)=$ $9.06, p<.001$. Composite means appear in Figure 2. Fast-starter women $(M=-4.62 ; C I=$ -4.67 to -4.56 ) were most pronounced in citing family success; their CI did not overlap with that of any other group. The other groups were more inclined to claim financial and work success, with very-educated/partnered men $(M=-5.40 ; C I=-5.54$ to -5.26$)$ and women $(M=-5.36 ; C I=-5.61$ to -5.11$)$, and educated-single women $(M=-5.42 ; C I=-5.62$ to $-5.21)$ most pronounced in this tendency. Several other groups had CIs within the range of -5.3 to -4.8 .

\section{Discussion}

The Wisconsin Longitudinal Study has allowed us to look back in time and create a rare portrait of emerging adulthood in the 1950s and ' 60 s, well before current research on emerging adulthood was introduced (Arnett, 2000). Our general predictions centered on transition-to-adulthood clusters we expected to emerge from a large sample of 1957 high school graduates, and how members of the different clusters would fare at midlife. The WLS clusters that emerged were roughly of the types envisioned (i.e., similar to ones from people who were in their 20s in the 1990s and 2000s, but with greater percentages exhibiting early marriage and family formation, and lower percentages attaining higher education). WLS participants indeed ranged from very early to very late onset of marriage, parenthood, and paid labor, and amassed varying levels of education.

There were two main hypotheses regarding how members of the clusters would fare down the road. One hypothesis was that individuals who pursued an emerging adult-type lifestyle in the late 1950s and into the 1960s, characterized mainly by delayed marriage and childbearing, and higher education, would differ in midlife psychological distress from their high school peers who exhibited more traditional (for the 1950s and '60s) patterns of transitioning to adulthood. Opposing arguments were advanced for why the emerging adulttype individuals would exhibit poor psychological health at midlife (due to negative reactions from others for violating pro-marriage norms) or would exhibit good psychological health at midlife (due to material and professional benefits from their advanced education). The other, more definitive, hypothesis was that participants who pursued the more traditional pathways of the 1950s and "60s would report greater midlife success in the family domain than would their emerging-adult counterparts, but lesser work and financial success. The educated-singles cluster exhibited notably high depressive-symptom means, suggesting that violation of pro-marriage norms in young-adulthood may have triggered or exacerbated feelings of distress for decades to come. That norm-violation can intensify psychological distress over multiple decades would certainly be a provocative finding; however, it is also possible that other intervening events may have contributed to the educated singles' difficulties. The domain-success predictions were generally supported, although there were nuances in the results. To characterize the results, the following paragraphs provide brief synopses of how members of the six clusters fared at midlife.

The very-educated/partnered and moderately educated/family-oriented clusters displayed the lowest depressive symptoms among the groups in the 2003-05 assessment, when 
respondents were approximately 65 years old, and in 1992-93, when respondents were in their early 50s. The very-educated/partnered group, in particular, exhibited a psychological well-being composite reflecting personal growth and life purpose, rather than positive relations with others. Either of these orientations - growth/purpose or interpersonal relations - can be fulfilling for individuals. To theorists such as Damon (2008), however, development of a sense of purpose is a central task in the transition to adulthood and is crucial to a productive and satisfying life. Very-educated/partnered individuals' successful development of purpose may thus be the foundation for the other types of well-being they report. In addition, Wink and Staudinger (2016) suggest that maintaining positive relations with others may not challenge individuals as much as the pursuit of growth and purpose, as warm relations "may imply avoiding conflict rather than facing and working through it, as is characteristic of personality growth" (p. 308). Regarding self-perceived success in the different life domains, members of the very-educated/partnered and moderately educated/ family-oriented groups, like most of the other clusters, claimed greater relative success in financial and work matters, than in their family life. The combination of being romantically partnered after high school (thus adhering to the social norms of the time) and attaining educational and professional success appears to have led to life-trajectories relatively free of depressive symptoms.

The educated-singles cluster evidenced a mixed pattern of results. This group averaged relatively high levels of depressive symptoms in both follow-up assessments, especially the men in 1992-93. However, the educated singles also scored highly on growth and purpose, and financial/work success (especially the women). Assuming that education generally promotes good health, the relatively high depressive-symptom means among the educated singles in midlife suggest some possible residual distress over feeling out-of-step with societal marriage norms or possibly even facing hostility toward their single status in the late 1950 s and early '60s. Some of these individuals may have formed social networks of fellow singles (and others with similar interests) in their early-adult years, thus insulating them from potentially negative perceptions of single people in the larger culture (see Alwin, Cohen, and Newcomb, 1991, on subcultures within larger cultures). However, not all educated singles may have been able to do so.

The fast-starter group scored relatively high on depression symptoms at both follow-up assessments (especially the women in 1992-93). Fast-starters were also among the highest groups in reporting positive relations with other people (relative to personal growth and life purpose) in regard to their psychological well-being. In addition, female fast-starters reported high family success (relative to financial/work success) to a much greater extent than did any other subgroup of participants. The overall picture for fast-starters appears to be that their family life, and interpersonal relationships more generally, went well. However, these positive developments did not appear to protect the fast-starters from later depressive symptoms. With members of this cluster having little (if any) education beyond high school, it is likely that their wages and occupational prospects stagnated in the 1980s and beyond relative to college graduates (Kirsch, Braun, Lennon, \& Sands, 2016), possibly contributing to their depressive symptoms. 
Finally, two clusters were focused on post-high school military and/or paid labor-force experience. The work/military-first cluster stood out primarily for its high depressive symptoms in both the early 1990s (in women) and early 2000s (regardless of gender). Members of this cluster appeared to derive their psychological well-being predominantly from positive relations with others rather than personal growth/purpose, and their average on the domain-success composite was almost exactly in the middle between the extremes of family success and finance/work success. Winsborough (1978) suggested that the prospect of military service in earlier generations may have led young adults to speed up their other life transitions (e.g., marriage, parenthood, labor-force participation). Perhaps some military veterans in this cluster (predominantly men) suffered psychologically as a result of taking on roles sooner than would have been optimal given their abilities, interests, and preferences. U.S. involvement in the Vietnam War in the 1960s and '70s during an era of general political turmoil may also have harmed veterans' psychological health. For both men and women, jobs that one could obtain without higher education likely offered lower pay, benefits, and security than professional careers, perhaps leading to a lower quality of life in the long term. Gender discrimination against women (Helson, 1972) could have exacerbated the effects of their job characteristics on perceived work success (and possibly on depression).

Finally, the military/professional-aspiration group did not display a clear pattern on the depressive-symptom measure, falling somewhat toward the low side in 2003-05, but somewhat toward the high side in 1992-93. In addition, these participants fell roughly in the middle of the psychological well-being composite (between the extremes of positive relations with others and personal growth/purpose) and toward financial/work success rather than family success. Back when members of this group were high-school seniors, they knew of their interest in a career requiring a college education and, after early onset of marriage and childbearing, were well on their way to obtaining a bachelor's degree, on average. In the end, they appeared to be statistically average on most of the psychological-health measures, but did indicate financial/work success.

These results support the strategy of looking at combinations of life pursuits and roles in the educational, occupational, and family domains within clusters of similarly situated individuals. Such an approach mirrors a "morphogenic" perspective (Allport, 1962; Pelham, 1993) on personality and development. Three clusters, for example, averaged 16 years (i.e., a bachelor's degree) or more of education. However, the combination of high educational attainment with marriage and family formation (in the very-educated/partnered and moderately educated/family-oriented clusters) vs. higher education without marriage and family formation (in the educated-singles) carried very different implications for later depression.

Effect-sizes varied for the comparisons between clusters on health/well-being outcomes. One of the larger differences occurred on 1992-93 depressive symptoms between women in the work/military-first and very-educated/partnered clusters, with the former having a considerably higher mean. This difference fell approximately at a Cohen's $d$ value of .50, which Cohen (1988) describes as medium. However, many of the significant differences in this study were small in magnitude. $R^{2}$ values reported with each of the ANOVAs revealed that all of the independent variables (cluster, gender, and the SES covariate) in a given 
analysis collectively accounted for between $2-6 \%$ of the variance in the respective dependent variables. Focus should thus be on differences between clusters with the highest and lowest means on any given outcome measure, as these will most likely carry practical significance in everyday life.

What do these results, judged through a social-history lens, tell us? They suggest to us that the different clusters' patterns of psychological health at midlife were consistent with historical, economic, cultural, and military developments to which they had been exposed in the immediate post-high school years (e.g., pro-marriage norms, the Vietnam War) and beyond (e.g., the widening income spread between those with and without college educations, beginning in the 1980s). Further, whether different clusters' life choices adhered to or challenged dominant societal norms of the time also likely impacted their later health. These claims represent only our inferences of how major historical events might have affected individuals, however. Stewart and Healy (1989) theorized that events occurring during adolescence and young adulthood are likely to affect individuals' identity formation, with the impact being stronger the more discrepant the events are from individuals' prior worldviews. Many historical events of the 1960s (e.g., Civil Rights Movement, Women's Movement) would have been likely to challenge existing worldviews and prompt individuals to revisit their identities. More direct study of individuals' responses to historical events, along with further research to explicate processes of deviance and sanctions (Settersten, 2003) are warranted.

In addition, the present study can only partially address how historical events affect the transition to adulthood, as only one cohort was studied. Ideally, other cohorts would be followed to see if associations between life pursuits (as embodied in our clusters) and psychological health replicated over multiple cohorts or differed depending on historical contexts (Twenge, 2015). Because of the time involved in conducting lifespan longitudinal studies, however, it will likely be left to future generations of scholars to compare results from the present study with those of later cohorts.

What implications do the present findings hold for young people transitioning to adulthood as the year 2020 approaches? Predictions for these individuals' psychological health in 2050 and beyond must necessarily be speculative. However, if the principle holds true that normviolation can be hazardous, shifting norms could yield different findings from what we found. Whereas the 1950s and early 1960s appeared to have strong early-marriage norms, recent evidence suggests that parents are increasingly encouraging their children to delay marriage, in favor of completing their education and establishing financial stability (Regnerus \& Uecker, 2011). The norm-violators of the future would then be people who married in their late teens or early 20 s, perhaps producing worse psychological health in them, compared to those who remained single.

As with all research, the present study had its limitations. One is the possibility that some of the positive long-term health trends of groups such as the very-educated/partnered cluster could be residual effects of growing up in advantaged families. All analyses controlled for SES in the family of origin, but it is likely this measure could not capture all aspects of growing up in an advantaged environment. Other measures of SES were available in the 
WLS, but they tended to have large amounts of missing data. Another limitation is that the psychological-health items were not introduced until the 1992-93 wave. It is possible that those following an emerging-adult lifestyle in the 1950s and ' 60 s could have experienced greater distress relative to other groups during their 20 s, in contrast to their relatively positive well-being at midlife. The 1950s/'60s emerging adults' deviation from the earlymarriage norms of the era may have drawn societal scorn (or at least puzzled reactions from observers used to the traditional norms). Because the early WLS waves lacked health measures, however, we cannot test this conjecture. Among the measures that were available, most had adequate reliability. However, two subscales of Ryff's psychological well-being instrument had relatively low alpha reliability (in the .60s). Finally, the demographics of Wisconsin's population do not match those of the entire U.S., thus limiting the generalizability of the present findings.

In conclusion, today's 21st-century emerging adults appear to have had a group of forerunners, albeit comprising a smaller share of the total population, in the 1950s and 1960s. Further, the 1950s/'60s emerging adults appear to have fared well in health and wellbeing up through middle age (or even entering "young-old" status) in the 2000s, with the exception of relatively high mean depressive symptoms among the educated singles. Continued study is warranted of the health correlates of different life trajectories, mechanisms responsible for potential effects on health, and interventions to maximize quality of life for individuals who have followed all different types of life pathways.

\section{Acknowledgments}

This research uses data from the Wisconsin Longitudinal Study (WLS) of the University of Wisconsin-Madison. Since 1991, the WLS has been supported principally by the National Institute on Aging (AG-9775 and AG-21079), with additional support from the Vilas Estate Trust, the National Science Foundation, the Spencer Foundation, and the Graduate School of the University of Wisconsin-Madison. Since 1992, data have been collected by the University of Wisconsin Survey Center. A public use file of data from the Wisconsin Longitudinal Study is available from the Wisconsin Longitudinal Study, University of Wisconsin-Madison, 1180 Observatory Drive, Madison, Wisconsin 53706 and at http://www.ssc.wisc.edu/wlsresearch/data/. The opinions expressed herein are those of the authors.

\section{References}

Allport GW. The general and the unique in psychological science. Journal of Personality. 1962; 30:405-422. [PubMed: 13860641]

Alsop, R. The trophy kids grow up: How the Millennial Generation is shaking up the workplace. San Francisco: Jossey-Bass; 2008.

Alwin, DF., Cohen, RL., Newcomb, TM. Political attitudes over the life span: The Bennington women after fifty years. Madison: The University of Wisconsin Press; 1991.

Arnett JJ. Emerging adulthood: A theory of development from the late teens through the twenties. American Psychologist. 2000; 55:469-480. [PubMed: 10842426]

Arnett, JJ. Emerging adulthood: The winding road from the late teens through the twenties. New York: Oxford University Press; 2004.

Arnett JJ, Žukauskienė R, Sugimura K. The new life stage of emerging adulthood at ages 18-29 years: Implications for mental health. The Lancet: Psychiatry. 2014; 1:569-576. [PubMed: 26361316]

Bicchieri, C. The grammar of society: The nature and dynamics of social norms. New York: Cambridge University Press; 2006. 
Clever M, Segal DR. The demographics of military children and families. Future of Children. 2013; 23:13-39. Retrieved from: https://www.princeton.edu/futureofchildren/publications/docs/Chapter \%201.pdf. [PubMed: 25518690]

Cohen, J. Statistical power analysis for the behavioral sciences. 2nd. Hillsdale, NJ: Erlbaum; 1988.

Congressional Budget Office. The All-Volunteer Military: Issues and performance. 2007. Retrieved from: https://www.cbo.gov/sites/default/files/110th-congress-2007-2008/reports/07-19militaryvol_0.pdf

Coontz S. Aren't you glad you weren't single fifty years ago? Match.com Blog. 2011 Retrieved from: http://blog.match.com/2011/02/04/aren\%E2\%80\%99t-you-glad-you-weren\%E2\%80\%99t-singlefifty-years-ago/.

Damon, W. The path to purpose: How young people find their calling in life. New York: Free Press; 2008.

Elder, GH, Jr. Children of the Great Depression: Social change in life experience. Chicago: University of Chicago Press; 1974.

Florida, R. The rise of the creative class: And how it's transforming work, leisure, community and everyday life. New York: Perseus Book Group; 2002.

Grice JW, Iwasaki M. A truly multivariate approach to MANOVA. Applied Multivariate Research. 2007; 12:199-226.

Helson R. The changing image of the career woman. Journal of Social Issues. 1972; 25:33-46.

Helson R, Picano J. Is the traditional role bad for women? Journal of Personality and Social Psychology. 1990; 59:311-320. [PubMed: 2213496]

Herd, P. The Wisconsin Longitudinal Study. Washington, DC: Presentation to the Financial Literacy Research Consortium; 2010 Nov. Retrieved from: http://www.rand.org/content/dam/rand/www/ external/events/2010/11/18/wisconsin-longitudinal-study.pdf

IBM. K-Means Cluster (QUICK CLUSTER) results sensitive to case order [Technical Note]. (not dated) Retrieved from: http://www-01.ibm.com/support/docview.wss?uid=swg21476878

Judis, JB., Teixeira, R. The emerging Democratic majority. New York: Lisa Drew/Scribner; 2002.

Kirsch, I., Braun, H., Lennon, ML., Sands, A. Choosing our future: A story of opportunity in America. Princeton, NJ: Educational Testing Service; 2016. Retrieved from: http:// opportunityproject.ets.org/assets/content/choosing-our-future.pdf

Kloep, M., Hendry, LB. Rejoinder to chapters 2 and 3: Critical comments on Arnett's and Tanner's approach. In: Arnett, JJ.Kloep, M.Hendry, LB., Tanner, JL., editors. Debating emerging adulthood: Stage or process?. New York: Oxford University Press; 2011. p. 107-120.

Kojima, H. Historical contexts for development. In: Valsiner, J., Connolly, KJ., editors. Handbook of developmental psychology. London: Sage; 2003. p. 72-87.

Krahn HJ, Howard AL, Galambos NL. Exploring or floundering? The meaning of employment and educational fluctuations in emerging adulthood. Youth and Society. 2015; 47:245-266.

Leonard, K. Moms are older than they used to be. U.S. News \& World Report. 2016 Jan 14. Retrieved from: http://www.usnews.com/news/blogs/data-mine/2016/01/14/cdc-the-median-age-of-firsttime-motherhood-is-increasing

Manly, BFJ. Multivariate statistical methods: A primer. Boca Raton, FL: Chapman \& Hall/CRC; 2005.

Mathews, TJ., Hamilton, BE. NCHS Data Brief (No. 21). Hyattsville, MD: National Center for Health Statistics; 2009. Delayed childbearing: More women are having their first child later in life. Retrieved from: http://www.cdc.gov/nchs/data/databriefs/db21.pdf

McDonald, TJ., editor. The historic turn in the human sciences. Ann Arbor, MI: University of Michigan Press; 1996.

Miller M. Living history: Retracing the evolution of the PC and PC Magazine. PC Magazine. Mar 12.2002 Retrieved from: http://www.pcmag.com/article2/0,2817,1175818,00.asp.

Moen, P. Work over the gendered life course. In: Shanahan, MJ.Mortimer, JT., Johnson, MK., editors. Handbook of the life course. Vol. 2. Cham, Switzerland: Springer; 2016. p. 249-275.

Osgood, DW., Ruth, G., Eccles, JS., Jacobs, JE., Barber, BL. Six paths to adulthood. In: Settersten, RA., JrFurstenberg, FF., Jr, Rumbaut, RG., editors. On the frontier of adulthood: Theory, research, and public policy. Chicago: University of Chicago Press; 2005. p. 320-355. 
Payne, KK. Forming families (FP-11-08). National Center for Family \& Marriage Research; 2011. Retrieved from: http://ncfmr.bgsu.edu/pdf/family_profiles/file101794.pdf

Payton ME, Greenstone MH, Schenker N. Overlapping confidence intervals or standard error intervals: What do they mean in terms of statistical significance? Journal of Insect Science. 2003; 3 Article 34 (Online journal available at: http://jinsectscience.oxfordjournals.org/).

Pearce, NC., Parks, RA. Wisconsin Longitudinal Study staff. User's guide, Wisconsin Longitudinal Study instrumentation: 1957 to 2010. Madison, Wisconsin: University of Wisconsin; 2011. Retrieved from: http://www.ssc.wisc.edu/wlsresearch/documentation/flowcharts/ Full_Instrumentation_1957_2010_vers6_Final.pdf

Pelham BW. The idiographic nature of human personality. Journal of Personality and Social Psychology. 1993; 64:665-677. [PubMed: 8473983]

Regnerus, M., Uecker, J. Premarital sex in America: How young Americans meet, mate, and think about marrying. New York: Oxford University Press; 2011.

Reifman A, Arnett JJ, Colwell MJ. Emerging adulthood: Theory, assessment, and application. Journal of Youth Development. 2007 Summer;2(1) Available online at: http://www.nae4ha.com/archives.

Reilly C, Wang C, Rutherford M. A rapid method for the comparison of cluster analyses. Statistica Sinica. 2005; 15:19-33.

Ryff C. Happiness is everything, or is it? Explorations on the meaning of psychological well-being. Journal of Personality and Social Psychology. 1989; 57:1069-1081.

Ryff C, Keyes CLM. The structure of psychological well-being revisited. Journal of Personality and Social Psychology. 1995; 69:719-727. [PubMed: 7473027]

Sandefur, GD., Eggerling-Boeck, J., Park, H. Off to a good start? Postsecondary education and early adult life. In: Settersten, RA., JrFurstenberg, FF., Jr, Rumbaut, RG., editors. On the frontier of adulthood: Theory, research, and public policy. Chicago: University of Chicago Press; 2005. p. 292-319.

Segal DR, Segal MW. America's military population. Population Bulletin. 2004; 59 Retrieved from: http://www.prb.org/source/acf1396.pdf.

Settersten RA Jr. A time to leave home and a time never to return? Age constraints on the living arrangements of young adults. Social Forces. 1998; 76:1373-1400.

Settersten, RA, Jr. Age structuring and the rhythm of the life course. In: Mortimer, JT., Shanahan, MJ., editors. Handbook of the Life Course. New York: Kluwer Academic/Plenum; 2003. p. 81-98.

Settersten, RA., Jr, Ray, BE. Not quite adults: Why 20 -somethings are choosing a slower path to adulthood, and why it's good for everyone. New York: Bantam; 2010.

Springer KW, Hauser RM. An assessment of the construct validity of Ryff's scales of psychological well-being: Method, mode, and measurement effects. Social Science Research. 2006; 35:10801102.

Stewart AJ, Healy JM. Linking individual development and social changes. American Psychologist. 1989; 44:30-42.

Thornton A, Young-DeMarco L. Four decades of trends in attitudes toward family issues in the United States: The 1960s through the 1990s. Journal of Marriage and the Family. 2001; 63:1009-1037.

Twenge, JM. The age in which we live and its impact on the person. In: Reynolds, KJ., Branscombe, NR., editors. Psychology of change: Life contexts, experiences, and identities. New York: Psychology Press; 2015. p. 44-58.

U.S. Census Bureau. Median age at first marriage: 1890 to present. 2015. Retrieved from: https:// www.census.gov/hhes/families/files/graphics/MS-2.pdf

Veroff, J., Douvan, E., Kulka, RA. The inner American: A self-portrait from 1957 to 1976. New York: Basic Books; 1981.

Viera AJ, Garrett JM. Understanding interobserver agreement: The kappa statistic. Family Medicine. 2005; 37:360-363. [PubMed: 15883903]

Wink P, Staudinger UM. Wisdom and psychosocial functioning in later life. Journal of Personality. 2016; 84:306-318. [PubMed: 25546500] 
Winsborough, HH. Statistical histories of the life cycle of birth cohorts: The transition from schoolboy to adult male. In: Taeuber, KE.Bumpass, LL., Sweet, JA., editors. Social demography. New York: Academic Press; 1978. p. 231-259.

Wisconsin Longitudinal Study. Graduates, siblings, and spouses (version 13.01, machine-readable data file, R. M. Hauser \& W. H. Sewell, principal investigators). Madison, WI: University of Wisconsin-Madison; 1957-2005. Retrieved from: http://www.ssc.wisc.edu/wlsresearch/ documentation/

Wisconsin Longitudinal Study. A note on factor weighted SES scores. Madison, WI: University of Wisconsin Center for Demography of Health and Aging; 1999. last updated Retrieved from: http:// www.ssc.wisc.edu/wlsresearch/documentation/appendices/L/cor689.asc

Wisconsin Longitudinal Study. Documentation of scales in Wisconsin Longitudinal Study. Madison, WI: University of Wisconsin Center for Demography of Health and Aging; 2008. Retrieved from: http://www.ssc.wisc.edu/wlsresearch/documentation/scales/WlsScalesDoc_Nov2010.pdf 


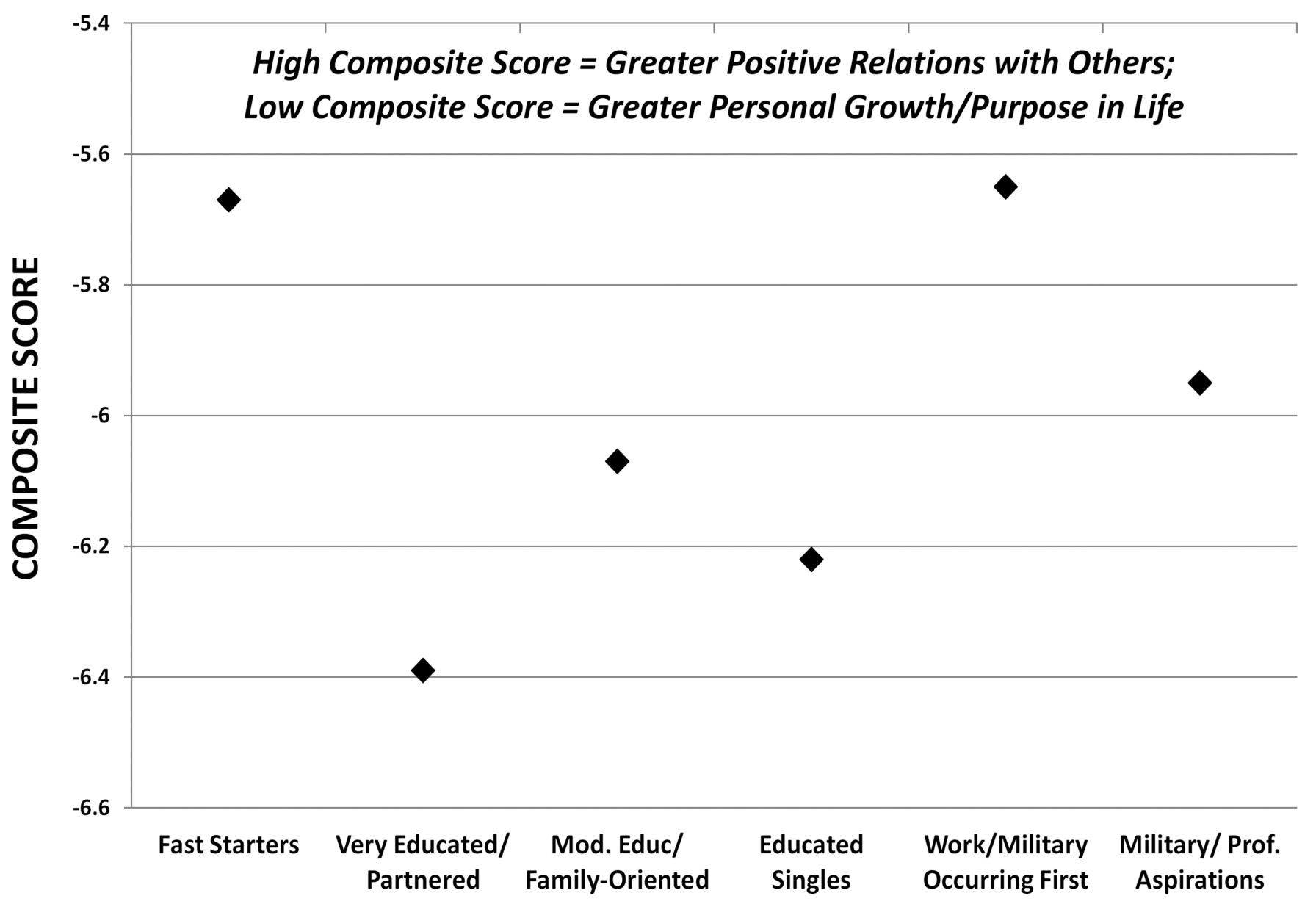

Figure 1.

Comparison of the six clusters on psychological well-being composite derived from multivariate analysis of variance. Higher means represent greater relative well-being in interpersonal relationships than in other areas, whereas lower means represent greater relative well-being in areas of personal growth and purpose in life. 


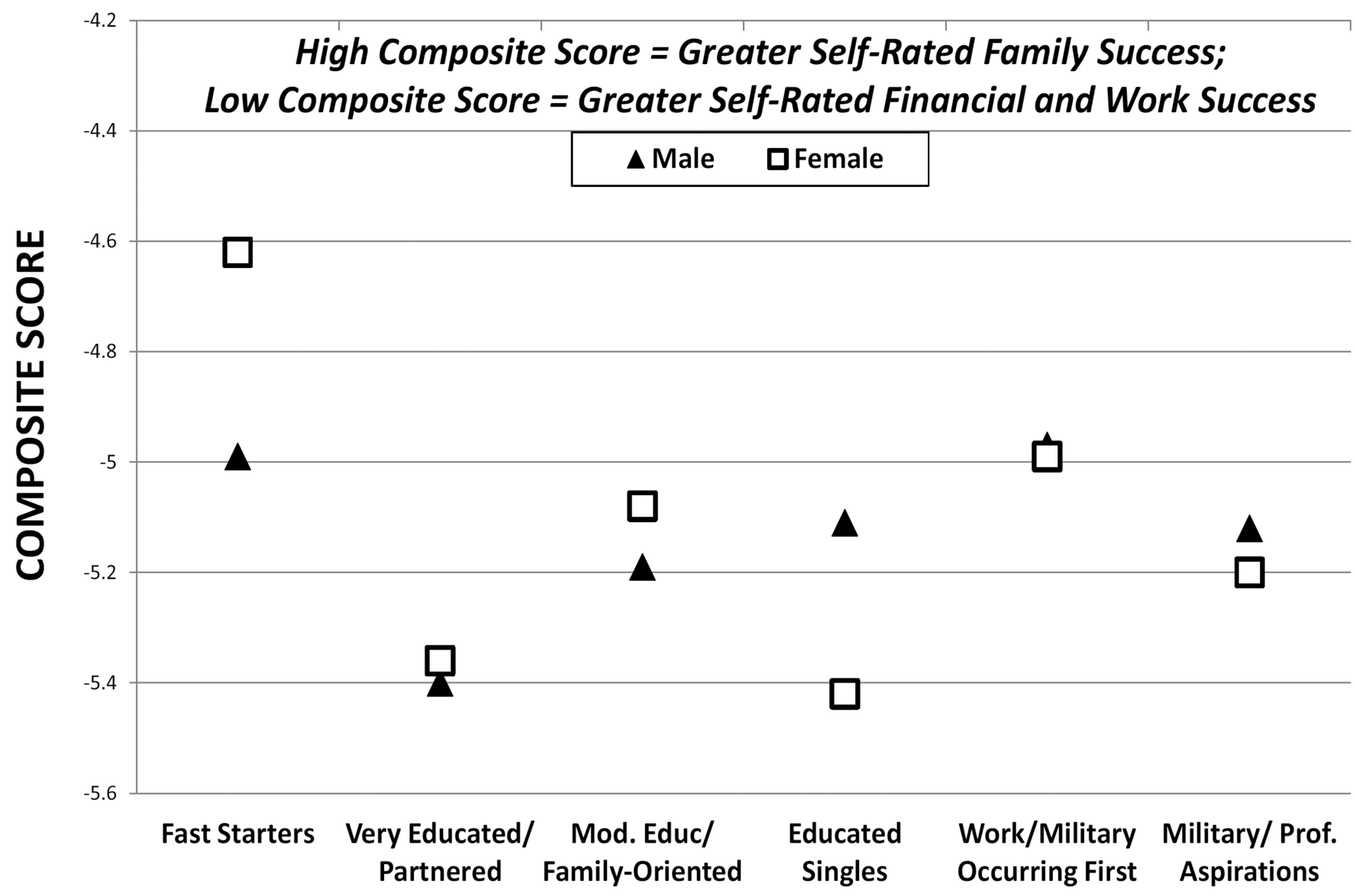

Figure 2.

Comparison of men and women in the six clusters on life-success composite derived from multivariate analysis of variance. Higher means represent greater relative success in family life than in other domains, whereas lower means represent greater relative success in financial/work domains. 

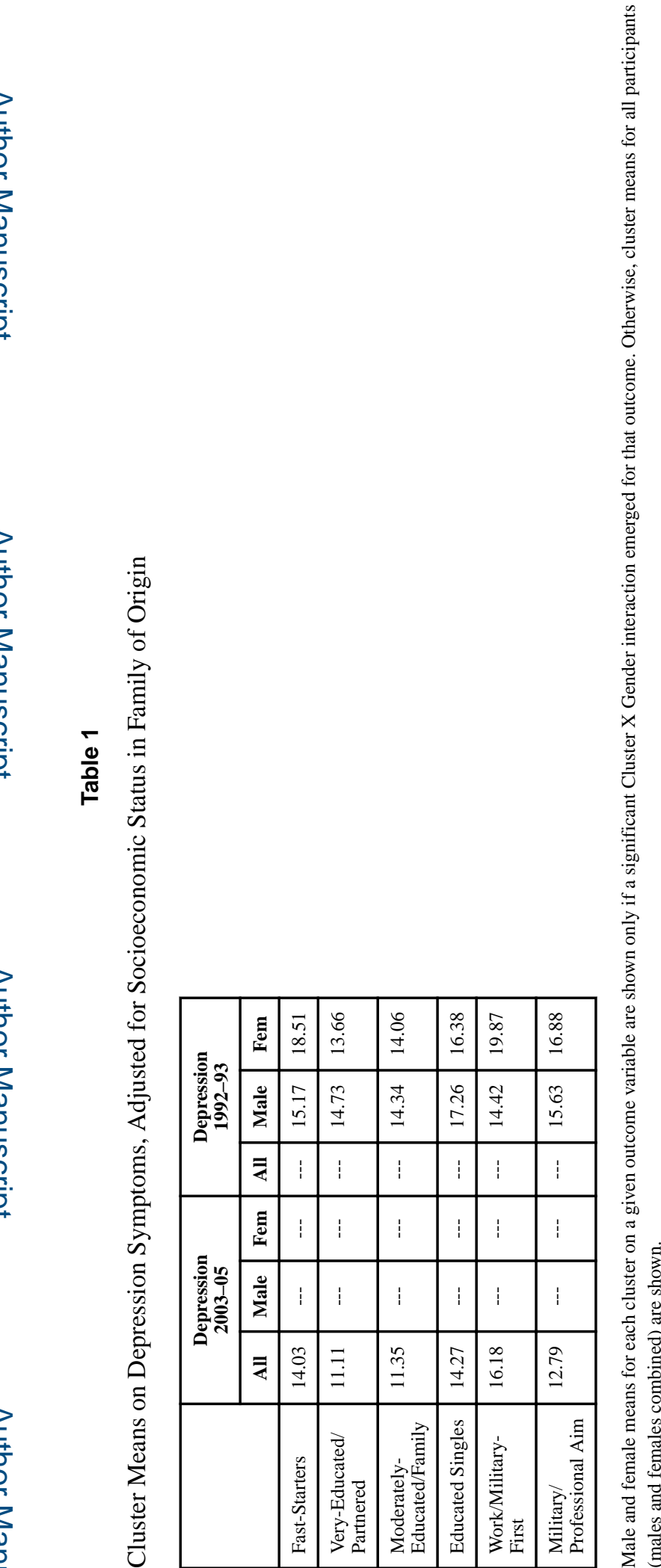

J Adult Dev. Author manuscript; available in PMC 2017 September 19. 